\title{
Mediating behavior of the pigeon during delayed responding
}

\author{
DONALD MELTZER and DAVID E. NOBBE \\ Southern Illinois University, Carbondale, Illinois 62901
}

\begin{abstract}
Five pigeons learned an indirect delayed response in which one of two keys was lighted to begin a trial. A peck on that key turned off the key light and started the delay interval. Both keys were dark during the delay interval, and the same stimulus appeared on both keys at the end of the delay interval. Subjects then were reinforced for pecking the key that had been lit to start the trial. The pigeons' accuracy decreased as the length of delay interval increased. Four of the five pigeons also pecked at the darkened keys during the delay interval. Three of these four birds pecked at the correct key less frequently as delay intervals were lengthened. All four of the birds that responded during the delay interval pecked the incorrect key at increased rates as the delay interval was lengthened. The results are consistent with the view that mediating responses are maintained by delayed reinforcement of the simple discrimination between dark and light keys at the beginning of the trial. At longer delay intervals, the reinforcement is less effective and mediating behavior breaks down in the manner just described, to produce lower accuracy.
\end{abstract}

The first delayed response experiment was done by Hunter in 1913. He studied rats, dogs, raccoons, and children in a study that required the subject to withhold responses to a discriminative stimulus until after a period of time known as the delay interval had elapsed. This procedure has come to be known as an indirect delayed response (e.g., Fletcher, 1965; Spear, 1978) because the subject had to learn to respond to the discriminative stimulus before the delayed response procedure could be introduced. The direct delayed response differed in that the subject could observe the reinforcement being concealed at a specific location prior to the delay interval. Many studies since 1913 have examined the delayed response procedure. Recent reviews of this literature by Fletcher (1965) and Spear (1978) have concluded that the procedures and apparatus employed in an experiment are at least as important as, and perhaps more important than, the particular species in determining accuracy as a function of the delay interval.

In spite of the fact that many variables have been shown to affect delayed response performance, one persistent hypothesis is that subjects may engage in some type of overt mediating behavior during the delay interval. The mediating behavior most frequently described was an orienting response in which the subject looked or pointed toward the location of the hidden reinforcement (or the location at which the discriminative stimulus had been displayed) during the delay interval (e.g., Fletcher, 1965 , p. 136). Although such a possibility has often been discussed, the supporting data were either qualitative descriptions of behavior (e.g., French, 1959; Miles, 1957) or measurements of spontaneous activity (Fletcher, 1965).

The assumption that pigeons would engage in some type of overt mediating behavior when they were performing a delayed response has never been put to the test. Previous studies of delayed responding (Smith, 1967) and delayed alternation (Hearst, 1962) have not reported the pigeon's behavior during the delay interval. Any number of potential mediating responses exist, but the most likely candidate for such a response is keypecking. The keypeck response is probable in pigeons even when there is no contingency between pecking and food (e.g., Brown \& Jenkins, 1968), and preliminary work in our laboratory indicated that pigeons would peck a darkened key during delay intervals.

If keypecks occurred during the delay interval and were regarded as mediating responses, several questions would arise. As accuracy decreased at longer intervals, would there be a correlation with changes in mediating behavior? If there were such a correlation, what types of changes in mediating behavior would occur?

\section{METHOD}

\section{Subjects}

The subjects were five pigeons maintained at $80 \%$ of their free-feeding weights. Aside from the food received in the experimental chamber, the birds also received a supplementary ration after each session. Water was always available in the home cage.

\section{Apparatus}

The experimental chamber (BRS-Foringer) was $50 \mathrm{~cm}$ long $\mathrm{x}$ $35 \mathrm{~cm}$ high. The front wall contained two response keys, $3 \mathrm{~cm}$ in diameter, located $25 \mathrm{~cm}$ above the grid floor and $7.5 \mathrm{~cm}$ from each wall. The food hopper was located behind a $5 \times 4 \mathrm{~cm}$ opening centered on the midline of the front wall. Two lamps (GE 757) mounted behind a $7.5 \times 35 \mathrm{~cm}$ piece of white Plexiglas at the top of the front wall served as a houselight. The intensity of the houselight was $14.7 \mathrm{~mL}$, as measured by an SEI photometer. An in-line display unit was mounted directly behind the 
response key. Tape readers, electromechanical switching equipment, and counters were located in an adjacent room.

\section{Procedure}

The pigeons were shaped to peck each response key and to eat from the grain magazine. The delayed response procedure was then introduced. A trial began when one of the response keys was illuminated by a yellow light while the houselight was on. When the subject pecked the lighted key, the key was darkened. Both keys remained dark during the delay interval, but the houselight remained on. At the end of the delay interval, both keys were illuminated by a white cross. Pecking the key on which the yellow light had been displayed produced $4 \mathrm{sec}$ of access to a hopper filled with Purina Pigeon Chow and extinguished the stimuli on both response keys. A response on the key that was dark prior to the delay interval extinguished the stimuli on both response keys and also turned off the houselight for $4 \mathrm{sec}$. The next trial began immediately after the reinforcement or the period of darkness. If the pigeon had responded correctly, there was an equal probability that the stimulus starting the next trial would be on the same side as the stimulus that had started the preceding trial or on the opposite side. If the subject had responded incorrectly, the next trial was always begun by a stimulus on the same side. Sessions continued until a subject had earned 30 reinforcements.

During the first 12 sessions, the delay interval was 2 sec. It was then increased to $7.5 \mathrm{sec}$ for 12 sessions, after which it was reduced to $5.0 \mathrm{sec}$ for the next 12 sessions. In succeeding 12-session blocks, the delay interval was $7.5 \mathrm{sec}, 10 \mathrm{sec}, 15 \mathrm{sec}$, $20 \mathrm{sec}$, and $30 \mathrm{sec}$. The duration of the delay interval was held constant within a session, so that changes in mediating behavior could be related to specific delay intervals. Obviously, a procedure in which the delay interval changed from trial to trial would make it impossible for the bird to know which interval was being used on any given trial and therefore prevent the bird from adjusting its mediating behavior accordingly.

\section{RESULTS}

Figure 1 shows the relationship between each subject's accuracy and the length of the delay interval. The data were taken from the last six sessions at each delay

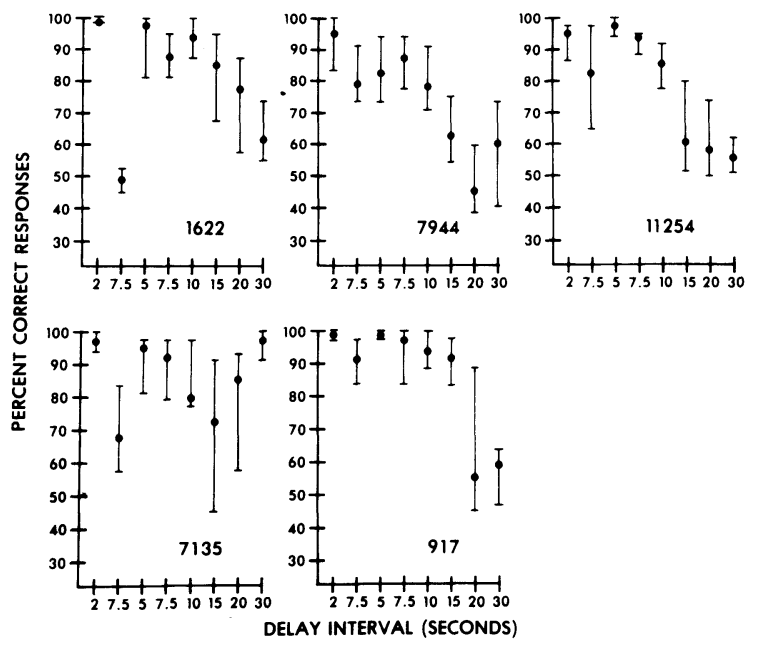

Figure 1. Median accuracy and the range of accuracy are shown for the last six sessions at each delay duration in the above figure. The sequence of delay intervals is the sequence in which they were presented to the subjects. interval duration. With the exception of Pigeon 7135, all subjects were less accurate as the delay interval increased. However, it may also be seen that accuracy dropped abruptly when subjects were first shifted from a $2.5-\mathrm{sec}$ delay interval to a 7.5-sec delay interval. Reducing the delay to $5.0 \mathrm{sec}$ caused an improvement in accuracy. When the delay interval then was lengthened to $7.5 \mathrm{sec}$, accuracy remained higher than it was during the first block of sessions using a 7.5-sec delay. Pigeon 7135 showed an unusual pattern of decreasing accuracy as delays were increased from 5.0 to $15.0 \mathrm{sec}$ and improved accuracy at 20 and 30 sec. In fact, this bird's accuracy at $30 \mathrm{sec}$ was approximately equal to its accuracy at $2 \mathrm{sec}$.

The first question about keypecks during the delay interval was whether they occurred at all and, if they did, how they were distributed between the keys. Table 1 shows these data from the last six sessions at each delay interval for all but the $2.0-\mathrm{sec}$ delay. Repeated equipment malfunctions at the beginning of the experiment produced unreliable results, and this accounts for the exclusion of those rates.

Except for 7135 , the pigeons usually maintained a moderate response rate during the delay interval. During the shorter delays, these responses were almost entirely on the correct key. At delays of $15 \mathrm{sec}$ or more, all subjects except 7135 usually made some responses on the incorrect key.

The relationship between median accuracy and median response rate during the delay interval was most consistent across subjects when the delay was first reduced from $7.5 \mathrm{sec}$ to $5.0 \mathrm{sec}$. All subjects had higher median accuracy after the shorter delay, and all but 7135 also increased the rate at which they pecked the correct key during the delay. However, the effect of increasing the delay interval over blocks of sessions did not have the same effect on all subjects over the rest of the experiment.

Table 1 shows that three pigeons, 1622, 7944, and 917 , tended to respond at lower rates on the correct key during the delay as the delay interval was lengthened. On the other hand, 11254 tended to have higher median response rates on the correct key at longer delays, and 7135 made very few delay interval responses regardless of the length of delay. All subjects except 7135 also tended to respond at higher median rates on the incorrect key as the duration of the delay interval increased.

The question of whether these changes in delay interval response rates could be changes in mediating behavior was examined by looking at their correlation with accuracy. Table 2 shows the correlation coefficients between median accuracy and median response rates for all but the 2-sec delay. Pigeon 7135 was excluded from the table because of its very low rate of delay interval responses. The coefficients for rates on the correct and incorrect keys are presented separately, and all coefficients are based on median values. It is apparent that although there was a correlation between the rate at 
Table 1

Accuracy and Delay Interval Response Rate (in Responses per Second) on Correct and Incorrect Keys as a Function of Length of Delay (in Seconds)

\begin{tabular}{|c|c|c|c|c|}
\hline \multirow[b]{3}{*}{ Delay } & \multicolumn{4}{|c|}{ Response Rate } \\
\hline & \multicolumn{2}{|c|}{ Correct Key } & \multicolumn{2}{|c|}{ Incorrect Key } \\
\hline & Median & Range & Median & Range \\
\hline 2.0 & \multicolumn{4}{|c|}{ Subject 1622} \\
\hline 7.5 & .07 & $.05-.17$ & .00 & $.00-.08$ \\
\hline 5.0 & .60 & $.34-.80$ & .00 & $.00-.01$ \\
\hline 7.5 & .55 & $.49-.87$ & .02 & $.00-.05$ \\
\hline 10.0 & .53 & $.35-.77$ & .01 & $.00-.03$ \\
\hline 15,0 & .48 & $.24-.72$ & .04 & $.00-.09$ \\
\hline 20.0 & .40 & $.13-.51$ & .07 & $.06-.09$ \\
\hline 30.0 & .14 & $.08-.25$ & .06 & $.02-.09$ \\
\hline 2.0 & \multicolumn{4}{|c|}{ Subject 7944} \\
\hline 7.5 & .04 & $.03-.06$ & .00 & $.00-.02$ \\
\hline 5.0 & .13 & $.05-.18$ & .00 & $.00-.02$ \\
\hline 7.5 & .14 & $.12-.16$ & .01 & $.00-.02$ \\
\hline 10.0 & .11 & $.07-.17$ & .01 & $.00-.02$ \\
\hline 15.0 & .08 & $.05-.12$ & .03 & $.01-.07$ \\
\hline 20.0 & .03 & $.02-.05$ & .01 & $.00-.02$ \\
\hline 30.0 & .14 & $.02-.25$ & .06 & $.00-.09$ \\
\hline 2.0 & \multicolumn{4}{|c|}{ Subject 11254} \\
\hline 7.5 & .28 & $.22-.62$ & .00 & $.00-.01$ \\
\hline 5.0 & .47 & $.40-.65$ & .00 & $.00-.00$ \\
\hline 7.5 & .37 & $.05-.60$ & .02 & $.00-.04$ \\
\hline 10.0 & .60 & $.50-.76$ & .03 & $.01-.04$ \\
\hline 15.0 & .55 & $.39-.87$ & .16 & $.05-.48$ \\
\hline 20.0 & 1.02 & $.40-1.36$ & .43 & $.35-.53$ \\
\hline 30.0 & .74 & $.36-.82$ & .41 & $.24-.57$ \\
\hline 2.0 & \multicolumn{4}{|c|}{ Subject 7135} \\
\hline 7.5 & .06 & $.01-.09$ & .00 & $.00-.00$ \\
\hline 5.0 & .02 & $.00-.04$ & .00 & $.00-.00$ \\
\hline 7.5 & .01 & $.00-.02$ & .00 & $.00-.00$ \\
\hline 10.0 & .02 & $.01-.02$ & .00 & $.00-.00$ \\
\hline 15.0 & .02 & $.01-.04$ & .00 & $.00-.00$ \\
\hline 20.0 & .01 & $.00-.06$ & .00 & $.00-.07$ \\
\hline 30.0 & .00 & $.00-.00$ & .00 & $.00-.00$ \\
\hline 2.0 & \multicolumn{4}{|c|}{ Subject 917} \\
\hline 7.5 & .80 & $.65-1.01$ & .01 & $.00-.03$ \\
\hline 5.0 & 2.15 & $1.90-2.32$ & .00 & $.00-.00$ \\
\hline 7.5 & 1.56 & $1.33-1.92$ & .00 & $.00-.04$ \\
\hline 10.0 & 1.52 & $.95-2.02$ & .02 & $.00-.06$ \\
\hline 15.0 & 1.22 & $1.14-1.41$ & .00 & $.00-.03$ \\
\hline 20.0 & .19 & $.11-.32$ & .07 & $.04-.13$ \\
\hline 30.0 & .15 & $.09-.18$ & .04 & $.03-.10$ \\
\hline
\end{tabular}

Note-Data are from the last six sessions at each delay value.

which subjects pecked the correct key during the delay interval and the accuracy of their responses, the correlation was not consistent from subject to subject. For some birds, such as 1622 and 917, there was a strong positive correlation between the two measures, whereas for 11254 the correlation was negative and slightly weaker. The correlation between median accuracy and response rate on the incorrect key was negative for all four subjects.

\section{DISCUSSION}

The aspect of the results most consistent with the general content of the delayed response literature was the decreasing accuracy of subjects as the length of the delay interval increased. While all the subjects were still responding at better than chance accuracy at $30-\sec$ delays, the functional relationship was clear for four of the five birds.

The question of primary interest was whether the relationship between keypecks during the delay interval served a mediating function. Again, four of the five subjects did peck during the delay interval, and these were the subjects that showed decreasing accuracy as the delay interval increased. Moreover, if keypecking is a mediating response, it should be controlled by the response that initiated the delay interval. That is, responses should be more likely on the key that started the delay interval than on the other key; this is just what happened.

Mediating response explanations of delay responding rarely describe the failures of mediating behavior that results in errors. At least two possibilities exist. The first is that subjects simply fail to maintain the mediating response as the delay interval increases. Such a failure could develop because the mediating response rate actually declines or because the mediating response rate does not increase enough to bridge the delay interval. In either case, the subject would not be emitting other competing, or incorrect, mediating responses that would lead to errors, but it would engage in behavior that was unrelated to the contingencies of reinforcement. Errors then would occur because the choice at the end of the delay interval was made on a chance basis.

The second possibility is that errors do not occur by chance. Mediating responses may be maintained during the delay interval, but the incorrect mediating response may intrude. This would be the case when the subject began to peck the key that had not been lit at the beginning of the trial.

For three of the subjects in this experiment, 1622, 7944, and 917 , it appeared that the frequency of correct mediating responses decreased as the delay was lengthened. At the same time, the probability that incorrect responses would be emitted increased. A fourth subject, 11254 , had negative correlations between accuracy and responses on both the correct and incorrect keys. Apparently, as the delay increased, this bird increased its rate of mediating responses but concomitantly increased the number of incorrect responses.

Finally, there was the question of how Pigeon 7135 was able to respond with extremely high accuracy after a 30 -sec delay even though it did not peck the key. Contrary to expectations, this subject did not stare at the correct key all through the delay interval. It moved in what appeared to be a random pattern on some trials, and on others it remained oriented toward the side of the chamber. When both keys were lit at the end of the trial, the pigeon looked back and forth between the two before making a choice. The type of delay interval behavior did not seem to be related to the stimulus that started the trial, although there may well have been subtle responses that were not detected by the experimenters. The critical point, of course, is that delayed response accuracy can be maintained by the pigeon in cases in which commonly observed mediating behaviors do not occur.

To summarize, it appears that most pigeons will engage in overt mediating behavior during delayed responding. However, some birds can respond accurately without such behavior. When

Table 2

Correlation Coefficients Between Median Accuracy and Median Response Rate on Correct and Incorrect Keys during the Delay Interval

\begin{tabular}{rcc}
\hline & & Incorrect \\
Subject & Correct Key & \\
\hline & & \\
1622 & .99 & -.20 \\
7944 & .47 & -.46 \\
11254 & -.70 & -.88 \\
917 & .90 & -.93 \\
\hline
\end{tabular}


mediating behavior occurs, it does involve orientation toward the site of the correct response, but incorrect orientations do occur and are more likely during long delays. The correlation between mediating responses and accuracy varies widely among subjects. While it may account for much of the variance in accuracy in some subjects, it may account for relatively little in others. Attempts to explain delayed response performance in terms of mediating responses must consider the idiosyncratic patterns of mediating behavior and not assume either qualitative or quantitative consistency of mediation between subjects.

\section{REFERENCES}

Brown, P. L., \& Jenkins, H. M. Auto-shaping of the pigeon's key-peck. Journal of the Experimental Analysis of Behavior, 1968, 11, 1-8.

Fletcher, H. L. The delayed response problem. In A. M.
Schrier, H. F. Harlow, \& F. Stollnits (Eds.), Behavior of nonhuman primates (Vol. 1). New York: Academic Press, 1965.

FrenCh, G. M. Performance of squirrel monkeys on variants of delayed response. Journal of Comparative and Physiological Psychology, 1959, 52, 741-745.

HEARST, E. Delayed alternation in the pigeon. Journal of the Experimental Analysis of Behavior, 1962, 5, 225-231.

Hunte R, W. S. The delayed reaction in animals and children. Behavior Monographs, 1913, 2, 1-86.

Miles, R. C. Delayed-response learning in the marmoset and the macaque. Journal of Comparative and Physiological Psychology, 1957, 50, 352-355.

Sмiтн, L. Delayed discrimination and delayed matching in pigeons. Journal of the Experimental Analysis of Behavior, 1967, 10, 529-533.

SPEAR, N. E. The processing of memories: Forgetting and retention. Hillsdale, N.J: Erlbaum, 1978.

(Received for publication June 2, 1980.) 